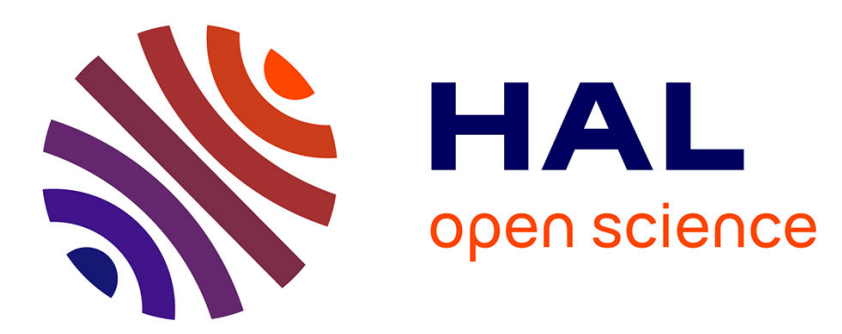

\title{
Measuring Multivariate Risk Preferences in the Health Domain
}

Arthur Attema, Olivier L'haridon, Gijs van de Kuilen

\section{To cite this version:}

Arthur Attema, Olivier L'haridon, Gijs van de Kuilen. Measuring Multivariate Risk Preferences in the Health Domain. Journal of Health Economics, 2019, 64, pp.15-24. 10.1016/j.jhealeco.2018.12.004 . halshs-01970236

\section{HAL Id: halshs-01970236 \\ https://shs.hal.science/halshs-01970236}

Submitted on 19 Feb 2019

HAL is a multi-disciplinary open access archive for the deposit and dissemination of scientific research documents, whether they are published or not. The documents may come from teaching and research institutions in France or abroad, or from public or private research centers.
L'archive ouverte pluridisciplinaire HAL, est destinée au dépôt et à la diffusion de documents scientifiques de niveau recherche, publiés ou non, émanant des établissements d'enseignement et de recherche français ou étrangers, des laboratoires publics ou privés. 


\section{Accepted Manuscript}

Title: Measuring Multivariate Risk Preferences in the Health Domain

Authors: Arthur E. Attema, Olivier l'Haridon, Gijs van de Kuilen

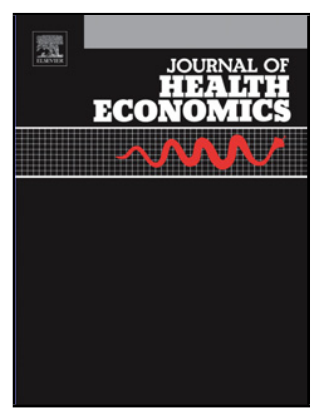

PII:

S0167-6296(18)30545-9

DOI: https://doi.org/10.1016/j.jhealeco.2018.12.004

Reference: JHE 2173

To appear in: Journal of Health Economics

Received date: 18 June 2018

Revised date: 18 December 2018

Accepted date: 20 December 2018

Please cite this article as: Attema AE, l'Haridon O, van de Kuilen G, Measuring Multivariate Risk Preferences in the Health Domain, Journal of Health Economics (2018), https://doi.org/10.1016/j.jhealeco.2018.12.004

This is a PDF file of an unedited manuscript that has been accepted for publication. As a service to our customers we are providing this early version of the manuscript. The manuscript will undergo copyediting, typesetting, and review of the resulting proof before it is published in its final form. Please note that during the production process errors may be discovered which could affect the content, and all legal disclaimers that apply to the journal pertain. 


\title{
Measuring Multivariate Risk Preferences in the Health Domain
}

\author{
October 2018
}

Arthur E. Attemaa, Olivier l'Haridon'b, Gijs van de Kuilenc

a (Corresponding author) Erasmus School of Health Policy \& Management, Erasmus University, P.O. Box 1738, 3000 DR Rotterdam, the Netherlands. Email: attema@eshpm.eur.nl, P: +31.10.408.91.29

b CREM, Université de Rennes 1, Rennes, France

c Tilburg School of Economics and Management, Tilburg University, Tilburg, The Netherlands

JEL Classification: B41, D90, I10 


\title{
Highlights
}

- Multivariate risk preferences are theoretically important to explain healthrelated behavior.

- However, empirical evidence on multivariate risk preferences is very scarce for health outcomes.

- We measure higher order risk preferences for health and wealth by means of the risk apportionment technique.

- We observe strong evidence for risk aversion and prudence for health and wealth in the gain domain, but more neutrality in the loss domain.

- In the multivariate setting, we find correlation aversion and cross-prudence for gains, and correlation seeking for losses.

- We conclude that there is clear evidence that multivariate risk preferences are sign-dependent.

\begin{abstract}
We investigate univariate and multivariate risk preferences for health (longevity) and wealth. We measure attitudes toward correlation and attitudes toward higher order dependence structures such as cross-prudence and cross-temperance, making use of the risk apportionment technique proposed by Eeckhoudt et al. (2007). For multivariate gains, we find correlation aversion and cross-prudence in longevity and wealth. For losses, we observe correlation seeking and cross-imprudence. We do not find clear evidence for cross-temperance. Our results indicate that longevity and wealth are considered to be substitutes for gains, but not for losses. Second, univariate (higher order) risk preferences are comparable for longevity and wealth, although somewhat closer to linearity for wealth. Third, we find evidence that attitudes toward dependence structures in the health domain are sign-dependent.
\end{abstract}

Key Words: multivariate risk attitudes, health, prudence, temperance. 


\section{Introduction}

Health and health care are surrounded by a lot of uncertainty, both in terms of diagnostic and treatment risk, risk of future diseases, and financial risks. As a result, it is widely recognized that risk preferences are an important determinant of health-related decisions. The recent theoretical literature has shown that many health-related behaviors in unidimensional settings should not only be governed by risk aversion, but that the higher order risk preferences prudence and temperance complement risk aversion in important ways (Courbage and Rey, 2006; Felder and Mayrhofer, 2014; Pauker, 2014). ${ }^{1}$ Intuitively, prudence governs how optimal behavior changes in the presence of a background risk, while temperance determines whether independent zero-mean risks should be aggregated or not (see Section 2 for details). For example, in in the wealth domain, agents who are prudent and temperate should save more, but should invest fewer of these savings in risky assets, than those who are neither prudent nor temperate (e.g. Eeckhoudt and Schlesinger, 2006; Gollier and Pratt, 1996; Kimball, 1990). In the case of health, Courbage and Rey (2006) observe that the level of prudence is a main determinant of the optimal level of prevention for health risks, while Felder and Mayrhofer (2014) show that prudence and temperance affect optimal medical test and treatment decisions. As a result, Pauker (2014) advocates that the study of higher order risk attitudes should receive priority on the research agenda of medical decision making.

Many health-related decisions are, however, not unidimensional; they are taken in the presence of other - often uncontrollable and undiversifiable - risks. For instance,

\footnotetext{
${ }^{1}$ Under expected utility (EU) maximization, risk aversion implies that the utility function is concave, prudence implies convex marginal utility, while temperance implies a negative fourth derivate of the utility function (e.g. Eeckhoudt and Schlesinger, 2006).
} 
the decision to purchase health insurance typically involves both health and wealth related risks, and the treatment of a particular disease may involve multiple independent health risks (comorbidities). Recent theoretical literature has shown that decisions in these multidimensional settings are not only driven by univariate risk preferences, but also by the multivariate risk preferences correlation aversion, crossprudence and cross-temperance by governing the interaction of univariate risk preferences for different attributes (Bleichrodt et al., 2003a; Dardanoni and Wagstaff, 1990; Ebert and van de Kuilen, 2018; Eeckhoudt et al., 2007; Rey and Rochet, 2004).

Taking health status and wealth as attributes, correlation aversion implies that the individual prefers to disaggregate fixed reductions in health and wealth, suggesting that, under expected utility (EU), the marginal utility of wealth increases as individuals become less healthy. If given a choice, a correlation averse individual would thus rather be rich in the state of the world in which she is sick than in the state in which she is healthy. Consequently, Eeckhoudt et al. (2007) show that a correlation averse individual whose health is declining over time will be inclined to save more in a simple two-period saving model. This is because the higher future wealth level allows her to better cope with the decline in health state.

Cross-prudence for health and wealth implies that the individual can better cope with the "pain" of facing a health risk when she has more wealth (and vice versa). As a result, an individual who is cross-prudent in health will spend more resources on preventive tertiary care if her future wealth risk increases (Eeckhoudt et al., 2007). Finally, an individual who is cross-temperate for health and wealth prefers to disaggregate health and wealth related risks over different states of nature (see Section 2 for details). 
Despite the importance of multivariate risk preferences for health-related behaviors from a theoretical perspective, there is surprisingly little empirical evidence regarding the prevalence of multivariate risk preferences in the health domain. In this study, we report the results of an experiment designed to elicit multi- and univariate higher order risk attitudes for health (longevity) and wealth, using the risk apportionment method introduced by Eeckhoudt et al. (2007). The main strength of this method is that it identifies multivariate risk preferences in a model-free way, i.e., without having to assume that individuals maximize a particular preference model such as EU. This is especially important given the fact that EU has often been found to fail as an accurate descriptive model of decision making in the health domain (e.g. Bleichrodt and Pinto, 2000; Bleichrodt et al., 2001; Loomes and McKenzie, 1989). Another strength of the measurement method is that is based on direct choices between two lotteries, making it well-suited for experimentation.

We make the following contributions to the literature on risk preferences in the health domain. First, we contribute to the fast-emerging literature on higher order risk preferences ( e.g. Deck and Schlesinger, 2014, 2018; Ebert and van de Kuilen, 2018; Ebert and Wiesen, 2014; Noussair et al., 2014; see Trautmann and van de Kuilen, 2018 for an overview). Only Krieger and Mayrhofer (2012) have elicited higher order risk attitudes in a health context, where they observed risk aversion and prudence. Krieger and Mayrhofer (2012) used monetary outcomes to proxy suffering from a disease. The advantage of this approach is that real incentives can be used, but the downside of the approach is that it is invalid if subjects value being ill and receiving less money differently. For this reason - and to avoid combining real incentives for one attribute with hypothetical incentives for another - we use hypothetical outcomes for wealth and longevity in this study. An advantage of this approach is that we are able to investigate 
higher order risk preferences in the health domain for significant outcomes. Although it is common practice in experimental economics to adopt a real incentive scheme, there is evidence suggesting there are no systematic differences in the results obtained with hypothetical incentives compared to real incentives for monetary outcomes (e.g., Abdellaoui et al., 2011; Bardsley et al., 2009; Cohen et al., 2016).

Second, we provide model-free direct evidence on whether individuals exhibit a nonlinear preference toward correlation for wealth and health (longevity). Several papers have investigated attitudes toward correlation for wealth and health indirectly by estimating the interaction between the marginal utility of wealth and health status, finding mixed evidence (Brown et al., 2015; Domeij and Johannesson, 2006; Edwards, 2008; Evans and Viscusi, 1991; Finkelstein et al., 2013; Gyrd-Hansen, 2016; Lillard and Weiss, 1997; Sloan et al., 1998; Tengstam, 2014; Viscusi and Evans, 1990). Other papers have investigated attitudes toward correlation between longevity and health states, generally finding correlation seeking for chronic health states, e.g., people typically prefer to live either long without pain or short with pain rather than living long with pain or short without pain (e.g. Pliskin et al., 1980; Wakker, 2010). We take longevity and wealth as attributes and use a model-free approach, i.e., without assuming that individual maximize a particular preference model such as EU.

Third, we provide the first empirical measurements of the prevalence of crossprudence and cross-temperance for longevity and wealth in our sample. As shown by Eeckhoudt et al., (2007), saving behavior in the presence of health risks is determined by these risk traits. In a survey of retired individuals, Edwards (2008) found indirect evidence for cross-temperance for wealth and health by observing that the proportion of risky financial assets held by respondents' decreases with increases in perceived 
future health risk. We are the first to test this conjecture directly in a controlled environment without making the assumption that individuals maximize EU.

Fourth, we investigate whether higher order risk preferences for longevity and multivariate risk preferences for longevity and wealth are sign-dependent. Previous literature has shown that attitudes towards risk depend crucially on whether outcomes are in the gain or in the loss domain (Tversky and Kahneman, 1992). Several recent papers have studied the robustness of higher order risk preferences toward framing of the outcomes (Deck and Schlesinger, 2010; Ebert and van de Kuilen, 2018; Ebert and Wiesen, 2011; Maier and Rüger, 2011). The common finding of prudence and temperance for wealth appears to be robust to such framing effects. In most of these studies however, subjects are asked to apportion either improvements (gains) or reductions (losses) across equally likely states of nature. The final outcomes of the lotteries are kept constant by manipulating the initial endowment from/to which these reductions or improvements are added/subtracted. As noticed by Bleichrodt and van Bruggen (2018), this manipulation does not affect the reference point of subjects if one uses the expected value of a lottery, the maximum of the minimum outcomes of a lottery, or the status quo as a reference point. The fact that these studies did not replicate the commonly found risk aversion for gains and risk seeking for losses for moderate probabilities, indeed suggests that these studies did not induce a shift in the reference point. Bleichrodt and van Bruggen (2018) do observe sign-dependence for prudence preferences in a setting where outcomes are framed as reductions or improvements compared to a (salient) initial endowment. We investigate whether multivariate risk preferences toward wealth and longevity are sign-dependent by considering the apportionment of reductions and improvements of wealth and 
longevity, while keeping initial endowments constant. ${ }^{2}$

We observe pervasive univariate risk aversion and prudence for monetary gains combined with risk aversion and prudence for gains in longevity. In the loss domain, however, we observe a shift toward more neutrality for risk and prudence for outcomes in euros and outcomes in life years. More importantly, individuals are correlation averse for wealth and longevity for gains, but correlation seeking for wealth and longevity for losses, suggesting that attitudes toward correlation might be sign-dependent. Finally, in the gain domain we observe cross-prudence for wealth, which implies part of precautionary savings by households might be driven by the desire to protect oneself against future longevity risks with higher wealth. More generally, our findings provide evidence on the validity of assumptions underlying models on demand for health insurance, prevention behavior and demand for medical care.

The remainder of this paper is organized as follows. Section 2 introduces notation and describes the risk apportionment technique. Section 3 presents the experimental design and Section 4 gives the results. We end the paper with a discussion in Section 5.

\section{Background}

\subsection{Univariate Risk preferences}

Suppose an individual is endowed with an initial wealth $W$ and an initial longevity $H$. We assume that the individual always prefers more wealth to less wealth and more longevity to less longevity. In what follows we assume that all variables are chosen such that final wealth and final longevity levels always remain strictly positive. Let $w_{1}$ and $w_{2}$

\footnotetext{
${ }^{2} \mathrm{~A}$ constant initial endowment induces a change in reference point if subjects use the expected value or the maximum of the minimum outcomes of a lottery as a point of reference, as has recently been found; in particular, Baillon et al. (2017) observe that the majority of subjects use the status quo or the maximum of the minimum outcomes as their reference points in a high stakes experiment.
} 
denote fixed monetary amounts and let $[x ; y]$ denote a prospect yielding either $x$ or $y$ with equal (50/50) chance. Risk aversion for wealth is defined as a preference between the two prospects depicted in Figure 1.

A

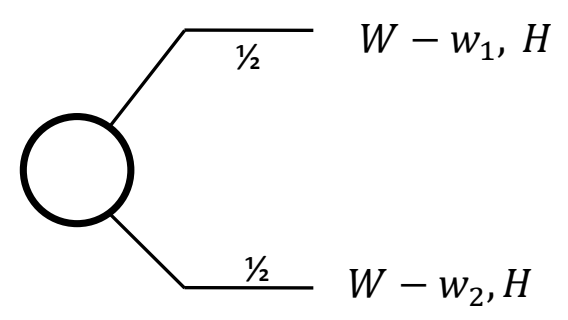

B

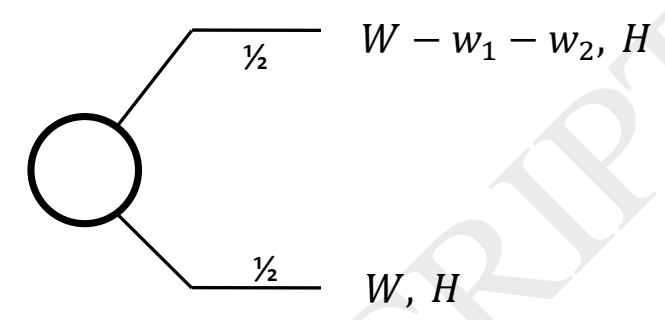

Figure 1: A behavioral condition of univariate risk aversion for wealth

As can be seen in Figure 1, the choice between the prospect A and B amounts to whether the individual prefers to aggregate or disaggregate the fixed wealth reductions across equally likely states of nature. If the individual prefers to disaggregate these fixed wealth reductions, she prefers prospect A and the individual is said to be risk averse for wealth. On the other hand, if the individual prefers to aggregate these fixed wealth reductions, she prefers prospect B and the individual is said to be risk seeking for wealth. Eeckhoudt and Schlesinger (2006) show that the choice for prospect A (B) implies that the utility function for wealth is concave (convex). Risk aversion for longevity can be defined in an analogous way by considering the apportionment of fixed reductions in longevity $h_{1}$ and $h_{2}$ instead of fixed reductions in wealth, as depicted in Figure 2 below.

A



B

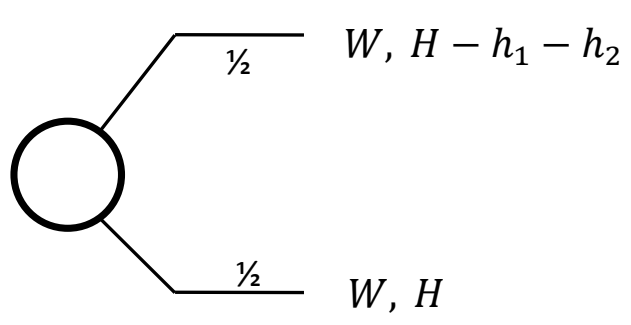


Figure 2: Behavioral condition of univariate risk aversion for longevity

The individual is said to be risk seeking (averse) for longevity if she prefers to (dis)aggregate $h_{1}$ and $h_{2}$ across equally likely states of nature, i.e., if she prefers prospect A to prospect B in Figure 2 .

Eeckhoudt and Schlesinger (2006) show that any $n$ th-order risk attitude can be defined in a more general framework, i.e., via risk apportionment, by considering the apportionment of zero-mean health and wealth risks instead of considering the apportionment of fixed reductions in health and wealth. For example, to define univariate prudence, the fixed reductions $w_{2}$ and $h_{2}$ are replaced by a zero-mean risk wealth $\widetilde{w}_{2}$ and zero-mean longevity risk $\widetilde{h}_{2}$ in Figure 1 and Figure 2 , respectively. A prudent individual prefers to disaggregate the sure loss in the first outcome and the zero-mean risk of the second outcome in two different states of nature, rather than aggregating them. For example, an individual exhibiting univariate prudence for wealth will always prefer to attach the zero-mean risk $\widetilde{w}_{2}$ to the state with the higher wealth $(W$, in prospect $\mathrm{A})$ than to the state with the lower wealth $\left(W-w_{1}\right.$, in prospect $\left.\mathrm{B}\right)$. Similarly, an individual exhibiting univariate prudence for longevity will always prefer to apportion the zero-mean risk $\tilde{h}_{2}$ to the state with the higher longevity $(H)$ than to the state with the lower longevity $\left(H-h_{1}\right)$. Figure 2 illustrates univariate prudence for longevity. 
A

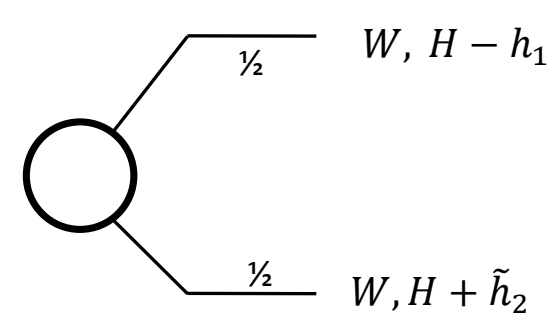

B

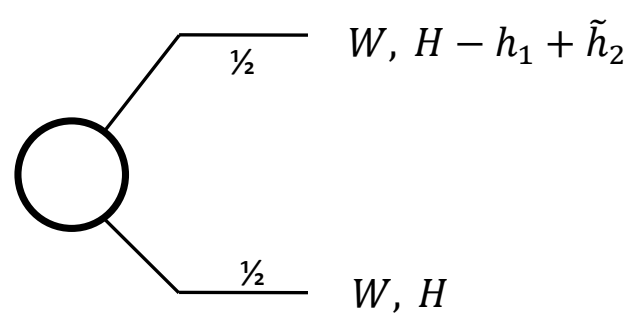

Figure 3: Behavioral condition of univariate prudence for longevity

Thus, univariate prudence for longevity implies that the individual can better cope with a longevity risk when she lives longer. Univariate temperance, the fourth order risk attitude, can similarly be defined as a preference for risk apportionment by considering the apportionment of two independent zero-mean wealth risks $\widetilde{w}_{1}$ and $\widetilde{w}_{2}$ and two independent zero-mean longevity risks $\tilde{h}_{1}$ and $\tilde{h}_{2}$. Univariate temperance for wealth is defined as a preference for prospect $\left[\left(W+\widetilde{w}_{1}, H\right) ;\left(W+\widetilde{w}_{2}, H\right)\right]$ over prospect $[(W+$ $\left.\left.\widetilde{w}_{1}+\widetilde{w}_{2}, H\right) ;(W, H)\right]$, while univariate temperance for longevity is defined as a preference for prospect $\left[\left(W+\widetilde{w}_{1}, H\right) ;\left(W+\widetilde{w}_{2}, H\right)\right]$ over prospect $\left[\left(W+\widetilde{w}_{1}+\widetilde{w}_{2}, H\right) ;(W, H)\right]$. A temperate decision maker dislikes aggregating zero-mean risks in the same state of nature, i.e., the zero-mean risks are mutually aggravating. Under EU, univariate risk aversion, prudence and temperance for attribute $x$ imply $u_{\mathrm{xx}}<0, u_{\mathrm{xxx}}>0$, and $u_{\mathrm{xxxx}}<0$, respectively. ${ }^{3}$

\subsection{Multivariate risk preferences}

\footnotetext{
${ }^{3}$ Throughout this paper, we let $u(x, y)$ denote a two-attribute, four-times differentiable utility function. $u_{\mathrm{xx}}$ denotes the second derivative of the utility function with respect to attribute $x$. We follow the same convention for higher order and cross-derivatives, e.g., $u_{\mathrm{xy}}$ denotes the cross derivative of the utility function with respect to attribute $x$ and $y$.
} 
As shown by Eeckhoudt et al. (2007) the risk apportionment approach can also be used to define multivariate risk attitudes. A behavioral definition of correlation aversion, also called multivariate risk aversion, was first given by de Finetti (1952), Richard (1975), and Epstein and Tanny (1980). Correlation aversion between longevity and wealth is defined as the preference of prospect A over B depicted in Figure 4.

A

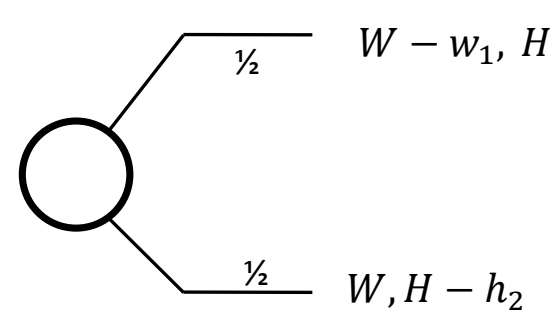

B

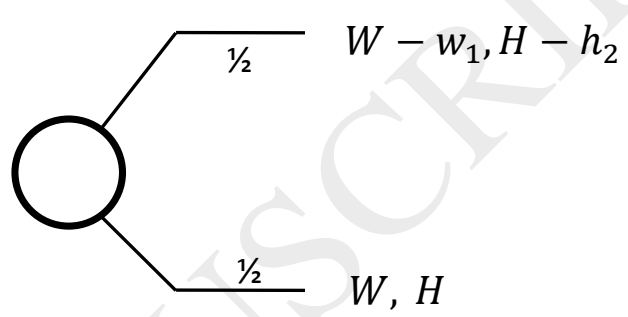

Figure 4: Behavioral definition of correlation aversion between wealth and longevity

As can be seen in Figure 4, the individual faces two fixed reductions in prospect A, whatever the state of nature. The realization of uncertainty determines the nature of the reductions: a reduction in wealth $w_{1}$ or a reduction in longevity $h_{2}$. In prospect B both reductions are aggregated in the same state of nature. Thus, the choice between prospect $\mathrm{A}$ and $\mathrm{B}$ amounts to whether the individual prefers to aggregate the fixed reductions in wealth and longevity or not. Correlation aversion (seeking) implies that an individual prefers a higher level of wealth in the case of lower (higher) longevity. Eeckhoudt et al. (2007) show that the choice for A implies that the cross-derivative of the utility function is negative, i.e., $u_{\mathrm{xy}} \leq 0$.

Eeckhoudt et al. (2007) define two types of cross-prudence in a multivariate setting, depending on the nature of the zero-mean risk. An individual is cross-prudent for longevity if she prefers prospect $\left[\left(W+\widetilde{w}_{1}, H\right) ;\left(W, H-h_{2}\right)\right]$ to the prospect $[(W+$ $\left.\left.\widetilde{w}_{1}, H-h_{2}\right) ;(W, H)\right]$. A cross-prudent individual for longevity prefers to disaggregate a 
sure reduction of longevity and a zero-mean wealth risk in two different states of nature, rather than pooling them together in the same state of nature. Thus, cross-prudence for longevity implies that the individual can better cope with a wealth risk if her longevity is higher. Similarly, cross-prudence for wealth is defined as the preference for the prospect $\left[\left(W-w_{1}, H\right) ;\left(W, H+\tilde{h}_{2}\right)\right]$ over $\left[\left(W-w_{1}, H+\tilde{h}_{2}\right) ;(W, H)\right]$. Thus, cross-prudence for wealth implies that the individual prefers to disaggregate a fixed wealth loss and a zeromean longevity risk in two different states of nature, rather than pooling them together in the same state of nature.

Finally, cross-temperance for wealth and longevity is defined as the preference for prospect A over prospect B depicted in Figure 5.

A

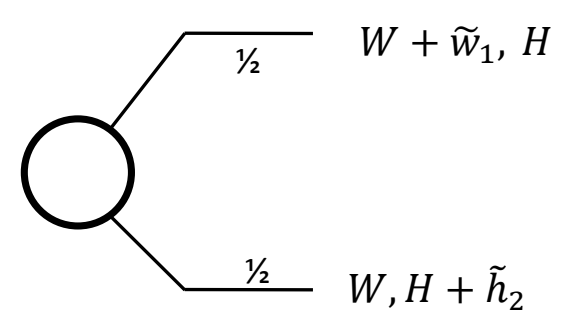

B



Figure 5: Behavioral definition of cross-temperance

As can be seen in the figure, the choice between A and B amounts to whether or not the individual prefers to aggregate the independent zero-mean risks $\widetilde{w}_{1}$ and $\tilde{h}_{2}$. In the words of Eeckhoudt et al. (2007) and Kimball (1993), for a cross-temperate individual the independent wealth and longevity risk are "mutually aggravating", and, hence, she prefers to disaggregate them and prefers prospect $A$.

\section{Experiment}




\subsection{Subjects}

The experiment was conducted at Erasmus University Rotterdam, the Netherlands, and was programmed in z-Tree (Fischbacher, 2007). In total, 98 subjects (43.9\% female) took part in sessions of up to four participants. Participants were remunerated in course credits. Upon arrival at the experiment, subjects we given oral instructions and were informed that there were no right or wrong answers. The experiment consisted of two separate parts. The first part concerned the elicitation of univariate risk preferences; the second part concerned the elicitation of multivariate risk preferences. At the start of each part, subjects read the written instructions and were required to answer several practice questions to check for understanding of the instructions. Online Appendix 2 details the instructions for both parts of the experiment. An elaborate description of all traits we used in the experiment is provided in Appendix A.

\section{2. $\quad$ Procedure and stimuli}

Subjects were asked to make a total of 69 choices between prospects yielding outcomes in terms of wealth and life expectancy. Within each part of the experiment (univariate vs. multivariate), the order of the choice tasks and the position of each lottery on the screen (left vs. right) was randomized. Subjects were endowed with $€ 240,000$ and 40 years of longevity. The 40 years are about 15 to 20 years less than the life-expectancy of the average subject in our sample. Because our experiment included improvements and reductions in life years, it was important to have a baseline value that was compatible with a reasonable final longevity in the gain domain. Regarding wealth, subjects were given a baseline endowment of $€ 240,000$. We stressed the fact that choices involving increments and decrements of wealth would be proposed during the experiment. It was 
also underlined that those increments and decrements could be safe (realized for sure) or risky. Lotteries were presented in a non-reduced form in order to stay as close as possible to the existing literature on higher order risk preferences.

Table 1 lists the choice tasks that were used in the experiment in the gain domain.

Table 1: Choice Tasks for Gains

\begin{tabular}{|c|c|c|c|c|}
\hline Task $^{a}$ & Trait & Prospect A & Prospect B & $\begin{array}{c}\text { Choice } \\
\%^{\mathrm{b}}\end{array}$ \\
\hline $1^{*}$ & \multirow{3}{*}{$\begin{array}{c}\text { Risk } \\
\text { aversion for } \\
\text { wealth }\end{array}$} & $\begin{array}{l}{[(€ 240+€ 44,40 y) ;} \\
(€ 240+€ 20,40 y)]\end{array}$ & $\begin{array}{c}{[(€ 240+€ 44+€ 20,40 y) ;} \\
(€ 240,40 y)]\end{array}$ & $81.63 / 80.61$ \\
\hline 2 & & $\begin{array}{l}{[(€ 240+€ 32,40 y) ;} \\
(€ 240+€ 44,40 y)]\end{array}$ & $\begin{array}{c}{[(€ 240+€ 32+€ 44,40 y)} \\
(€ 240,40 y)]\end{array}$ & 81.63 \\
\hline 3 & & $\begin{array}{l}{[(€ 240+€ 20,40 y)} \\
(€ 240+€ 32,40 y)]\end{array}$ & $\begin{array}{c}{[(€ 240+€ 20+€ 32,40 y)} \\
(€ 240,40 y)]\end{array}$ & 79.59 \\
\hline 4 & \multirow{3}{*}{$\begin{array}{c}\text { Risk } \\
\text { aversion for } \\
\text { longevity }\end{array}$} & $\begin{array}{l}{[(€ 240,40 y+9 y)} \\
(€ 240,40 y+5 y)]\end{array}$ & $\begin{array}{c}{[(€ 240,40 y+9 y+5 y)} \\
(€ 240,40 y)]\end{array}$ & 87.76 \\
\hline $5^{*}$ & & $\begin{array}{l}{[(€ 240,40 y+7 y)} \\
(€ 240,40 y+9 y)]\end{array}$ & $\begin{array}{c}{[(€ 240,40 y+7 y+9 y)} \\
\quad(€ 240,40 y)]\end{array}$ & 91.84 / 86.73 \\
\hline 6 & & $\begin{array}{l}{[(€ 240,40 y+5 y)} \\
(€ 240,40 y+7 y)]\end{array}$ & $\begin{array}{c}{[(€ 240,40 y+5 y+7 y)} \\
(€ 240,40 y)]\end{array}$ & 85.71 \\
\hline 7 & \multirow{3}{*}{$\begin{array}{c}\text { Correlation } \\
\text { aversion }\end{array}$} & $\begin{array}{c}{[(€ 240+€ 20,40 y)} \\
(€ 240,40 y+9 y)]\end{array}$ & $\begin{array}{c}{[(€ 240+€ 20,40 y+9 y)} \\
(€ 240,40 y)]\end{array}$ & 74.49 \\
\hline $8^{*}$ & & $\begin{array}{l}{[(€ 240+€ 44,40 y)} \\
(€ 240,40 y+7 y)]\end{array}$ & $\begin{array}{c}{[(€ 240+€ 44,40 y+7 y)} \\
(€ 240,40 y)]\end{array}$ & $75.51 / 72.45$ \\
\hline 9 & & $\begin{array}{l}{[(€ 240+€ 32,40 y)} \\
(€ 240,40 y+5 y)]\end{array}$ & $\begin{array}{c}{[(€ 240+€ 32,40 y+5 y)} \\
(€ 240,40 y)]\end{array}$ & 80.61 \\
\hline 10 & \multirow{3}{*}{$\begin{array}{l}\text { Prudence for } \\
\text { wealth }\end{array}$} & $\begin{array}{l}{[(€ 240+€ 44,40 y)} \\
(€ 240 \pm € 20,40 y)]\end{array}$ & $\begin{array}{c}{[(€ 240+€ 44 \pm € 20,40 y)} \\
(€ 240,40 y)]\end{array}$ & 65.31 \\
\hline 11 & & $\begin{array}{c}{[(€ 240+€ 44,40 y) ;} \\
(€ 240+€(15,-5), 40 y)]\end{array}$ & $\begin{array}{c}{[(€ 240+€ 44+€(15,-5),, 40 y)} \\
(€ 240,40 y)]\end{array}$ & 51.02 \\
\hline $12^{*}$ & & $\begin{array}{c}{[(€ 240+€ 20,40 y)} \\
(€ 240 \pm € 5,40 y)]\end{array}$ & $\begin{array}{c}{[(€ 240+€ 20 \pm € 5,40 y)} \\
(€ 240,40 y)]\end{array}$ & $56.12 / 56.12$ \\
\hline 13 & \multirow{3}{*}{$\begin{array}{c}\text { Prudence for } \\
\text { longevity }\end{array}$} & $\begin{array}{l}{[(€ 240,40 y+9 y)} \\
(€ 240,40 y \pm 6 y)]\end{array}$ & $\begin{array}{c}{[(€ 240,40 y+9 y \pm 6 y)} \\
(€ 240,40 y)]\end{array}$ & 66.33 \\
\hline 14 & & $\begin{array}{c}{[(€ 240,40 y+7 y)} \\
(€ 240,40 y+(3,-1) y)]\end{array}$ & $\begin{array}{c}{[(€ 240,40 y+7 y+(3,-1) y) ;} \\
(€ 240,40 y)]\end{array}$ & 56.12 \\
\hline 15 & & $\begin{array}{l}{[(€ 240,40 y+5 y)} \\
(€ 240,40 y \pm 2 y)]\end{array}$ & $\begin{array}{l}{[(€ 240,40 y+5 y \pm 2 y)} \\
(€ 240,40 y)]\end{array}$ & 64.29 \\
\hline 16 & \multirow{3}{*}{$\begin{array}{c}\text { Cross- } \\
\text { Prudence for } \\
\text { longevity }\end{array}$} & $\begin{array}{l}{[(€ 240 \pm € 20,40 y)} \\
(€ 240,40 y+9 y)]\end{array}$ & $\begin{array}{c}{[(€ 240 \pm € 20,40 y+9 y)} \\
(€ 240,40 y)]\end{array}$ & 50 \\
\hline 17 & & $\begin{array}{l}{[(€ 240+€(15,-5), 40 y)} \\
\quad(€ 240,40 y+7 y)]\end{array}$ & $\begin{array}{c}{[(€ 240 \pm €(15,-5),, 40 y+7 y) ;} \\
(€ 240,40 y)]\end{array}$ & 39.8 \\
\hline 18 & & $\begin{array}{l}{[(€ 240 \pm € 5,40 y)} \\
(€ 240,40 y+5 y)]\end{array}$ & $\begin{array}{c}{[(€ 240 \pm € 5,40 y+5 y)} \\
(€ 240,40 y)]\end{array}$ & 43.88 \\
\hline $19 *$ & \multirow{3}{*}{$\begin{array}{c}\text { Cross- } \\
\text { Prudence for } \\
\text { wealth }\end{array}$} & $\begin{array}{l}{[(€ 240+€ 44,40 y)} \\
(€ 240,40 y \pm 6 y)]\end{array}$ & $\begin{array}{c}{[(€ 240+€ 44,40 y \pm 6 y)} \\
(€ 240,40 y)]\end{array}$ & $45.92 / 35.71$ \\
\hline 20 & & $\begin{array}{c}{[(€ 240+€ 32,40 y)} \\
(€ 240,40 y+(3,-1) y)]\end{array}$ & $\begin{array}{c}{[(€ 240+€ 32,40 y+(3,-1) y)} \\
(€ 240,40 y)]\end{array}$ & 35.71 \\
\hline 21 & & $\begin{array}{l}{[(€ 240+€ 20,40 y)} \\
(€ 240,40 y \pm 2 y)]\end{array}$ & $\begin{array}{c}{[(€ 240+€ 20,40 y \pm 2 y)} \\
(€ 240,40 y)]\end{array}$ & 37.76 \\
\hline 22 & $\begin{array}{c}\text { Temperance } \\
\text { for wealth }\end{array}$ & $\begin{array}{l}{[(€ 240 \pm € 20,40 y)} \\
(€ 240 \pm € 20,40 y)]\end{array}$ & $\begin{array}{c}{[(€ 240 \pm € 20 \pm € 20,40 y) ;} \\
(€ 240,40 y)]\end{array}$ & 50 \\
\hline
\end{tabular}




\begin{tabular}{|c|c|c|c|c|}
\hline 23 & & $\begin{array}{c}{[(€ 240 \pm € 20,40 y) ;} \\
(€ 240+€(15,-5), 40 y)]\end{array}$ & $\begin{array}{c}{[(€ 240 \pm € 20+€(15,-5),, 40 y)} \\
(€ 240,40 y)]\end{array}$ & 45.92 \\
\hline 24 & & $\begin{array}{l}{[(€ 240 \pm € 20,40 y)} \\
(€ 240 \pm € 5,40 y)]\end{array}$ & $\begin{array}{c}{[(€ 240 \pm € 20 \pm € 5,40 y)} \\
(€ 240,40 y)]\end{array}$ & 55.1 \\
\hline $25^{*}$ & \multirow{3}{*}{$\begin{array}{l}\text { Temperance } \\
\text { for longevity }\end{array}$} & $\begin{array}{l}{[(€ 240,40 y \pm 6 y)} \\
(€ 240,40 y \pm 6 y)]\end{array}$ & $\begin{array}{l}{[(€ 240,40 y \pm 6 y \pm 6 y)} \\
\quad(€ 240,40 y)]\end{array}$ & $61.22 / 55.1$ \\
\hline 26 & & $\begin{array}{c}{[(€ 240,40 y \pm 6 y)} \\
(€ 240,40 y+(3,-1) y)]\end{array}$ & $\begin{array}{c}{[(€ 240,40 y \pm 6 y+(3,-1) y) ;} \\
(€ 240,40 y)]\end{array}$ & 54.08 \\
\hline 27 & & $\begin{array}{l}{[(€ 240,40 y \pm 6 y)} \\
(€ 240,40 y \pm 2 y)]\end{array}$ & $\begin{array}{l}{[(€ 240,40 y \pm 6 y \pm 2 y)} \\
(€ 240,40 y)]\end{array}$ & 56.12 \\
\hline $28^{*}$ & \multirow{3}{*}{$\begin{array}{c}\text { Cross- } \\
\text { Temperance }\end{array}$} & $\begin{array}{l}{[(€ 240 \pm € 20,40 y)} \\
(€ 240,40 y \pm 6 y)]\end{array}$ & $\begin{array}{c}{[(€ 240 \pm € 20,40 y \pm 6 y)} \\
(€ 240,40 y)]\end{array}$ & 48.98 / 40.82 \\
\hline 29 & & $\begin{array}{c}{[(€ 240+€(15,-5), 40 y) ;} \\
(€ 240,40 y+(3,-1) y)]\end{array}$ & $\begin{array}{c}{[(€ 240+€(15,-5), 40 y+(3,-1) y) ;} \\
(€ 240,40 y)]\end{array}$ & 36.73 \\
\hline 30 & & $\begin{array}{l}{[(€ 240 \pm € 5,40 y)} \\
(€ 240,40 y \pm 2 y)]\end{array}$ & $\begin{array}{l}{[(€ 240 \pm € 5,40 y \pm 2 y)} \\
(€ 240,40 y)]\end{array}$ & 52.04 \\
\hline
\end{tabular}

Notes: All amounts in euro's $\mathrm{x} 1000 .{ }^{\text {a }} \mathrm{A}$ starred entry indicates that the choice task was repeated once as a consistency check. ${ }^{b}$ Denotes the percentage of choices that were consistent with the trait.

As can be seen in Table 1, the first 9 choices ( 3 for each trait) were designed to elicit univariate attitudes towards risk and correlation for wealth and longevity for gains. Attitudes towards (cross-) prudence for gains were measured in the next set of 12 choices. The final set of 9 choices was designed to elicit subjects' attitudes towards (cross-) temperance. For gains, 7 choices were repeated to probe the degree of consistency of responses.

In addition to these choice tasks, individuals were given 32 choice tasks involving the apportionment of losses, summarized in Table 2.

Table 2: Choice Tasks for Losses

\begin{tabular}{|c|c|c|c|c|}
\hline Task ${ }^{a}$ & Trait & Prospect A & Prospect B & $\begin{array}{c}\text { Choice } \\
\%^{\mathrm{b}}\end{array}$ \\
\hline 1 & \multirow{3}{*}{$\begin{array}{l}\text { Risk } \\
\text { aversion for } \\
\text { wealth }\end{array}$} & $\begin{array}{l}{[(€ 240-€ 6,40 y) ;} \\
(€ 240-€ 30,40 y)]\end{array}$ & $\begin{array}{c}{[(€ 240-€ 6-€ 30,40 y)} \\
(€ 240,40 y)]\end{array}$ & 42.86 \\
\hline 2 & & $\begin{array}{l}{[(€ 240-€ 18,40 y) ;} \\
(€ 240-€ 6,40 y)]\end{array}$ & $\begin{array}{c}{[(€ 240-€ 18-€ 6,40 y)} \\
(€ 240,40 y)]\end{array}$ & 48.98 \\
\hline 3 & & $\begin{array}{l}{[(€ 240-€ 30,40 y) ;} \\
(€ 240-€ 18,40 y)]\end{array}$ & $\begin{array}{c}{[(€ 240-€ 30-€ 18,40 y) ;} \\
(€ 240,40 y)]\end{array}$ & 53.06 \\
\hline 4 & \multirow{3}{*}{$\begin{array}{c}\text { Risk } \\
\text { aversion for } \\
\text { longevity }\end{array}$} & $\begin{array}{l}{[(€ 240,40 y-1 y)} \\
(€ 240,40 y-5 y)]\end{array}$ & $\begin{array}{c}{[(€ 240,40 y-1 y-5 y) ;} \\
(€ 240,40 y)]\end{array}$ & 42.86 \\
\hline $5^{*}$ & & $\begin{array}{l}{[(€ 240,40 y-3 y)} \\
(€ 240,40 y-1 y)]\end{array}$ & $\begin{array}{c}{[(€ 240,40 y-3 y-1 y)} \\
(€ 240,40 y)]\end{array}$ & $47.96 / 45.92$ \\
\hline 6 & & $\begin{array}{l}{[(€ 240,40 y-5 y)} \\
(€ 240,40 y-3 y)]\end{array}$ & $\begin{array}{c}{[(€ 240,40 y-5 y-3 y) ;} \\
(€ 240,40 y)]\end{array}$ & 51.02 \\
\hline
\end{tabular}




\begin{tabular}{|c|c|c|c|c|}
\hline 7 & \multirow{3}{*}{$\begin{array}{c}\text { Correlation } \\
\text { aversion }\end{array}$} & $\begin{array}{l}{[(€ 240-€ 30,40 y)} \\
(€ 240,40 y-1 y)]\end{array}$ & $\begin{array}{c}{[(€ 240-€ 30,40 y-1 y) ;} \\
(€ 240,40 y)]\end{array}$ & 29.59 \\
\hline 8 & & $\begin{array}{l}{[(€ 240-€ 6,40 y)} \\
(€ 240,40 y-3 y)]\end{array}$ & $\begin{array}{c}{[(€ 240-€ 6,40 y-3 y)} \\
(€ 240,40 y)]\end{array}$ & 35.71 \\
\hline 9 & & $\begin{array}{l}{[(€ 240-€ 18,40 y)} \\
(€ 240,40 y-5 y)]\end{array}$ & $\begin{array}{c}{[(€ 240-€ 18,40 y-5 y) ;} \\
(€ 240,40 y)]\end{array}$ & 31.63 \\
\hline 10 & \multirow{3}{*}{$\begin{array}{l}\text { Prudence for } \\
\text { wealth }\end{array}$} & $\begin{array}{l}{[(€ 240-€ 6,40 y)} \\
(€ 240 \pm € 20,40 y)]\end{array}$ & $\begin{array}{c}{[(€ 240-€ 6 \pm € 20,40 y)} \\
\quad(€ 240,40 y)]\end{array}$ & 52.04 \\
\hline 11 & & $\begin{array}{c}{[(€ 240-€ 18,40 y)} \\
(€ 240+€(15,-5), 40 y)]\end{array}$ & $\begin{array}{c}{[(€ 240-€ 18+€(15,-5), 40 y) ;} \\
(€ 240,40 y)]\end{array}$ & 43.88 \\
\hline 12 & & $\begin{array}{l}{[(€ 240-€ 30,40 y)} \\
(€ 240 \pm € 5,40 y)]\end{array}$ & $\begin{array}{c}{[(€ 240-€ 30 \pm € 5,40 y)} \\
(€ 240,40 y)]\end{array}$ & 51.02 \\
\hline 13 & \multirow{3}{*}{$\begin{array}{c}\text { Prudence for } \\
\text { longevity }\end{array}$} & $\begin{array}{l}{[(€ 240,40 y-1 y)} \\
(€ 240,40 y \pm 6 y)]\end{array}$ & $\begin{array}{c}{[(€ 240,40 y-1 y \pm 6 y)} \\
(€ 240,40 y)]\end{array}$ & 59.18 \\
\hline 14 & & $\begin{array}{c}{[(€ 240,40 y-3 y)} \\
(€ 240,40 y+(3,-1) y)]\end{array}$ & $\begin{array}{c}{[(€ 240,40 y-3 y+(3,-1) y) ;} \\
(€ 240,40 y)]\end{array}$ & 48.98 \\
\hline 15 & & $\begin{array}{l}{[(€ 240,40 y-5 y)} \\
(€ 240,40 y \pm 2 y)]\end{array}$ & $\begin{array}{l}{[(€ 240,40 y-5 y \pm 2 y)} \\
(€ 240,40 y)]\end{array}$ & 46.94 \\
\hline 16 & \multirow{3}{*}{$\begin{array}{l}\text { Cross- } \\
\text { Prudence for } \\
\text { longevity }\end{array}$} & $\begin{array}{l}{[(€ 240 \pm € 20,40 y)} \\
(€ 240,40 y-1 y)]\end{array}$ & $\begin{array}{c}{[(€ 240 \pm € 20,40 y-1 y)} \\
(€ 240,40 y)]\end{array}$ & 44.9 \\
\hline $17^{*}$ & & $\begin{array}{l}{[(€ 240+€(15,-5), 40 y)} \\
\quad(€ 240,40 y-3 y)]\end{array}$ & $\begin{array}{c}{[(€ 240 \pm €(15,-5),, 40 y-3 y)} \\
(€ 240,40 y)]\end{array}$ & $39.8 / 43.88$ \\
\hline 18 & & $\begin{array}{l}{[(€ 240 \pm € 5,40 y)} \\
(€ 240,40 y-5 y)]\end{array}$ & $\begin{array}{l}{[(€ 240 \pm € 5,40 y-5 y)} \\
(€ 240,40 y)]\end{array}$ & 48.98 \\
\hline 19 & \multirow{3}{*}{$\begin{array}{l}\text { Cross- } \\
\text { Prudence for } \\
\text { wealth }\end{array}$} & $\begin{array}{l}{[(€ 240-€ 6,40 y)} \\
(€ 240,40 y \pm 6 y)]\end{array}$ & $\begin{array}{l}{[(€ 240-€ 6,40 y \pm 6 y) ;} \\
(€ 240,40 y)]\end{array}$ & 46.94 \\
\hline 20 & & $\begin{array}{c}{[(€ 240-€ 18,40 y)} \\
(€ 240,40 y+(3,-1) y)]\end{array}$ & $\begin{array}{c}{[(€ 240-€ 18,40 y+(3,-1) y) ;} \\
(€ 240,40 y)]\end{array}$ & 43.88 \\
\hline 21 & & $\begin{array}{l}{[(€ 240-€ 30,40 y)} \\
(€ 240,40 y \pm 2 y)]\end{array}$ & $\begin{array}{c}{[(€ 240-€ 30,40 y \pm 2 y) ;} \\
(€ 240,40 y)]\end{array}$ & 47.96 \\
\hline
\end{tabular}

Notes: All amounts in euro's x1000. ${ }^{\text {a }} \mathrm{A}$ starred entry indicates that the choice task was repeated once as a consistency check. ${ }^{b}$ Denotes the percentage of choices that were consistent with the trait.

Again, the first 9 choices ( 3 for each trait) were designed to elicit univariate attitudes towards risk and correlation for wealth and longevity for losses. Attitudes towards (cross-) prudence for losses were measured in the next set of 12 choices. Since the apportionment concerned either a reduction or an improvement of the fixed outcome, the temperance questions were not different for gains and losses, and were only posed once. For losses, we repeated 2 choices to probe the degree of consistency of responses. 


\subsection{Analyses}

In our analyses, we use the amount of choices (out of 3) that are compatible with a given risk trait as our measurement of the strength of multi- and univariate risk preferences. One advantage of using the amount of choices as a measure of the strength of preference is that it allows us to directly compare our results with the existing literature where this measure is used most (Deck and Schlesinger, 2010, 2014; Ebert and van de Kuilen, 2018; Noussair et al., 2014). More importantly, the measure provides a ranking of subjects in terms of these preferences without having to assume that subjects maximize a particular preference model, such as EU. As a result, our analysis is modelfree in the sense that it retains validity if EU theory fails to accurately describe choice behavior (Starmer, 2000).

At the aggregate level, we report the mean number of choices and the average percentage of choices over tasks. At the individual level, we classify subjects depending on their choices, using the following criterion. A subject is classified according to a risk trait if the majority of her choices is consistent with that particular trait. Thus, for example, an individual is classified as being correlation averse (seeking) if the majority of her choices are compatible with correlation aversion (seeking). We perform a series of chi-squared tests to check whether the observed distribution of preferences deviates from the distribution that would be observed if subjects choose randomly. All tests show that choices were not made at random, with the notable exception of prudence for losses in longevity (see Online Appendix 1 for details). 


\section{Results}

\subsection{Consistency checks}

Subjects made the same choice in 77.44 percent of the repeated choices. This rate is consistent with the usually observed consistency rates in experiments (Stott, 2006). Given that the position of lotteries on the screen (left vs right) was randomly determined for every choice, consistency would not be observed to such a high degree of subjects would choose according to a heuristic such as always choosing left or right. We found some variability in consistency between the different tasks, with a (betweentask) standard deviation of 9.26 percent. ${ }^{4}$

\subsection{Univariate risk preferences}

Table 1 shows the aggregate results on univariate risk preferences. It shows both the mean number of choices and the standard deviation computed over the three choices. For gains, we found risk aversion to be the predominant pattern for both longevity and wealth, with a large majority of the choices compatible with risk aversion in both cases. Prudence is also a dominant feature for gains, for both attributes. Interestingly, Table 3 shows that we do not observe a significant deviation from neutrality for temperance for both wealth and longevity. This is in line with the mixed findings in the literature, where some papers have observed a preference for intemperance (e.g. Baillon et al., 2018;

\footnotetext{
${ }^{4}$ A closer look at the different repeated tasks shows that consistency rates were significantly higher for gains than for losses (Wilcoxon, p-value 0.017). We also found consistency to be higher on measures of risk aversion (univariate risk aversion and correlation aversion) than on measures of prudence (Wilcoxon, p-value $<0.001$ ) or temperance (Wilcoxon, p-value 0.001). We however found no difference in consistency between univariate tasks and multivariate tasks (Wilcoxon, p-value 0.931).
} 
Deck and Schlesinger, 2010), while others studies have found the opposite (e.g., Deck and Schlesinger 2014, Noussair et al., 2014).

For losses, we do not observe significant deviations form linearity; the mean preference is indicative of a neutral attitude toward risk and prudence for wealth and longevity. This finding corroborates recent results obtained by Bleichrodt and van Bruggen (2018), who observe a shift from risk aversion and modest prudence for gains to risk neutrality and imprudence for losses for monetary outcomes. We performed a series of chi-squared tests to check whether the observed distribution of preferences deviated from the distribution that would be observed if subjects choose randomly. All tests show that choices were not made at random, with the notable exception of prudence for losses in longevity.

Table 3: Univariate Risk Preferences Across Domains

\begin{tabular}{|c|c|c|c|c|}
\hline & $\begin{array}{c}\text { Gains, } \\
\text { mean }\end{array}$ & $\begin{array}{c}\text { Gains, } \\
\text { sd }\end{array}$ & $\begin{array}{c}\text { Losses, } \\
\text { mean }\end{array}$ & $\begin{array}{c}\text { Losses, } \\
\text { sd }\end{array}$ \\
\hline Risk aversion, Longevity & $2.65^{* * *}$ & 0.73 & 1.42 & 1.08 \\
\hline Prudence, Longevity & $1.87^{* * *}$ & 1.07 & 1.45 & 0.99 \\
\hline Temperance, Longevity & $1.71^{*}$ & 1.06 & & \\
\hline Risk aversion, Wealth & $2.43^{* * *}$ & 1.02 & 1.45 & 1.11 \\
\hline Prudence, Wealth & $1.72^{* *}$ & 1.01 & 1.53 & 0.99 \\
\hline Temperance, Wealth & 1.51 & 0.99 & & \\
\hline
\end{tabular}

Notes: $* * *(* * *)$ indicates a significant difference from 1.5 at the $1 \%(5 \%, 10 \%)$ level (one-sample two sided Wilcoxon-signed rank tests).

Table 4 shows the classification of individuals, based on their univariate risk preferences, together with the p-value of a one-sided binomial test for comparison between the percentage of individuals and 50\%. Table 4 confirms the aggregate findings. A large majority of individuals are classified as being risk averse for both longevity and wealth. We also find evidence for prudence for longevity and (marginally) 
for wealth. Temperance for longevity is marginally significant. For losses, we observe that there are more risk seekers than risk averters, but the proportion of risk seekers is not significantly different from $50 \%$ in either case. Imprudence for longevity and prudence for wealth are also not significant in the loss domain.

Table 4: Classification of individuals by context based on univariate risk preferences

\begin{tabular}{|l|l|l|l|l|}
\hline \% of individuals & Gains & $\mathrm{p}$-value & Losses & $\mathrm{p}$-value \\
\hline Risk averse, Longevity & 90.82 & $<0.01$ & 44.90 & 0.18 \\
\hline Prudent, Longevity & 62.24 & 0.01 & 45.92 & 0.24 \\
\hline Temperate, Longevity & 58.16 & 0.065 & & \\
\hline Risk averse, Wealth & 83.67 & $<0.01$ & 48.98 & 0.46 \\
\hline Prudent, Wealth & 58.16 & 0.065 & 56.12 & 0.13 \\
\hline Temperate, Wealth & 54.08 & 0.24 & & \\
\hline
\end{tabular}

In order to test the consistency of risk preferences across domains, we tested for the association between univariate risk preferences for longevity and univariate risk preferences for wealth. We find a significant association between risk preferences for longevity and wealth, at any order. First, risk attitudes for gains and losses are correlated (Fisher test, both p-values $<0.001$ ), with risk aversion (seeking) in the longevity domain associated with risk aversion (seeking) in the monetary domain. The same applies to prudence: prudent (imprudent) individuals in one domain are also prudent (imprudent) in the other domain (Fisher test, both p-values $<0.025$ for gains and losses). For temperance, we find a similar result (Fisher test, p-value <0.001). 
The aggregate results indicate that risk attitudes shift from risk aversion and prudence for gains toward risk- and prudence neutrality for losses. Such systematic sign-dependence of risk attitudes is not corroborated by the analysis at the individual level. A Fisher test shows no significant association between risk attitudes in the gain domain and risk attitudes in the loss domain ( $p$-value $=0.51$ for longevity and 0.59 for wealth). We also find no association in prudent behavior between gains and losses.

Individual results show that prudence is not systematically associated with risk aversion. The absence of relationship between risk attitudes and prudence holds for longevity and for wealth, for both gains and losses (Fisher tests, all p-values $>0.31$ ). Temperance (intemperance) is clearly associated with risk aversion (seeking), except for monetary losses (Fisher tests, all p-values $<0.03$, except for wealth and losses, $p$ value $=0.23$ ). Likewise, no systematic association between prudence and temperance is observed (Fisher tests, all p-values >0.09).

For gains, the combination of risk aversion, prudence and temperance corresponds to the modal univariate risk preference for both longevity and wealth (for 31.6 and 27.5 $\%$ of subjects, respectively). Combinations of risk aversion, prudence and intemperance, and risk aversion, imprudence and intemperance are also common. For losses, the combination of risk aversion, prudence and temperance corresponds to the modal univariate risk preference for wealth only (for $19.4 \%$ of subjects). For longevity, such risk preferences were not uncommon (17.3\% of subjects), but the modal preference implies a combination of risk seeking, imprudence and intemperance preferences (for $19.4 \%$ of subjects). 


\subsection{Multivariate risk preferences}

Table 5 shows the aggregate results concerning multivariate risk preferences.

Table 5: Multivariate Risk Preferences for Longevity and Wealth

\begin{tabular}{|c|c|c|c|c|}
\hline & $\begin{array}{c}\text { Gains, } \\
\text { mean }\end{array}$ & $\begin{array}{c}\text { Gains, } \\
\text { sd }\end{array}$ & $\begin{array}{c}\text { Losses, } \\
\text { mean }\end{array}$ & $\begin{array}{c}\text { Losses, } \\
\text { sd }\end{array}$ \\
\hline Correlation aversion & $2.31^{* * *}$ & 1.07 & $0.97^{* * *}$ & 1.09 \\
\hline $\begin{array}{c}\text { Cross-Prudence in } \\
\text { Longevity }\end{array}$ & 1.66 & 1.08 & 1.34 & 1.07 \\
\hline Cross-Prudence in Wealth & $1.81^{* * *}$ & 1.02 & 1.39 & 1.06 \\
\hline Cross-Temperance & 1.38 & 1.01 & & \\
\hline
\end{tabular}

Notes: ${ }^{* * *}(* *, *)$ indicates a significant difference from 1.5 at the $1 \%(5 \%, 10 \%)$ level (one-sample Wilcoxon-signed rank tests).

For gains, the modal choice pattern is indicative of a preference for correlation aversion for longevity and wealth; more than $76 \%$ of the choices are compatible with correlation aversion. Interestingly, for losses, we observe the opposite preference; $68 \%$ of choice are consistent with correlation seeking behavior. We thus extend the often observed sign-dependence for univariate risk attitudes to multivariate risk attitudes. Subjects prefer to disaggregate improvements in wealth and longevity, while they prefer to aggregate fixed reductions in these attributes.

Interestingly, we observe cross-prudence for wealth, but not so for longevity. Thus, people can better cope with a health risk in the future, if they have more wealth, which induced people to save precautionary to protect themselves against future health risk, according to theory (Eeckhoudt et al., 2007). For losses, we observe cross-prudence neutrality. Finally, we observe cross-temperance neutrality; people do not exhibit a nonlinear attitude toward aggregating or disaggregating wealth and longevity risks. 
Table 4 shows the classification of individuals, based on their multivariate risk preferences, together with the p-value of a one-sided binomial test for the comparison between the percentage of individuals and 50\%. Table 6 confirms the aggregate results. A large majority of individuals is classified as correlation averse for gains and correlation seeking for losses.

Table 6: Classification of individuals by context based on multivariate risk preferences

\begin{tabular}{|l|r|r|r|r|}
\hline \% of individuals & Gains & p-value & Losses & p-value \\
\hline Correlation aversion & 78.57 & $<0.01$ & 28.57 & $<0.01$ \\
\hline Cross-Prudence in Longevity & 52.04 & 0.38 & 42.86 & 0.09 \\
\hline Cross-Prudence in Wealth & 63.27 & $<0.01$ & 47.96 & 0.38 \\
\hline Cross-Temperance & 45.92 & 0.24 & & \\
\hline
\end{tabular}

While a majority of subjects (53 out of 98) exhibited correlation aversion in the gain domain and correlation seeking in the loss domain, we could not reject the hypothesis that both behaviors were unrelated (Fisher test, p-value 0.414). We also found evidence for cross-prudence for wealth in the gain domain. We only found marginal significance for cross-imprudence for longevity in the loss domain. For both gains and losses, we found significant associations between cross-prudence for longevity and crossprudence for wealth (Fisher tests, p-values 0.006 for gains and 0.002 for losses). Table 6 also shows we found no clear evidence against cross-temperance for longevity and wealth. 
Figure 6 shows the distributions of the number of correlation averse choices, in the gain and in the loss domain. It also shows the distributions of the number of correlation averse choices for risk seekers and risk averters for longevity and wealth. For gains, we found a clear association between correlation aversion and risk aversion for both longevity (Fisher test p-value 0.02) and wealth (Fisher test p-value 0.005). For losses, correlation seeking was associated with risk seeking for both longevity (Fisher test pvalue 0.001 ) and wealth (Fisher test p-value 0.002).
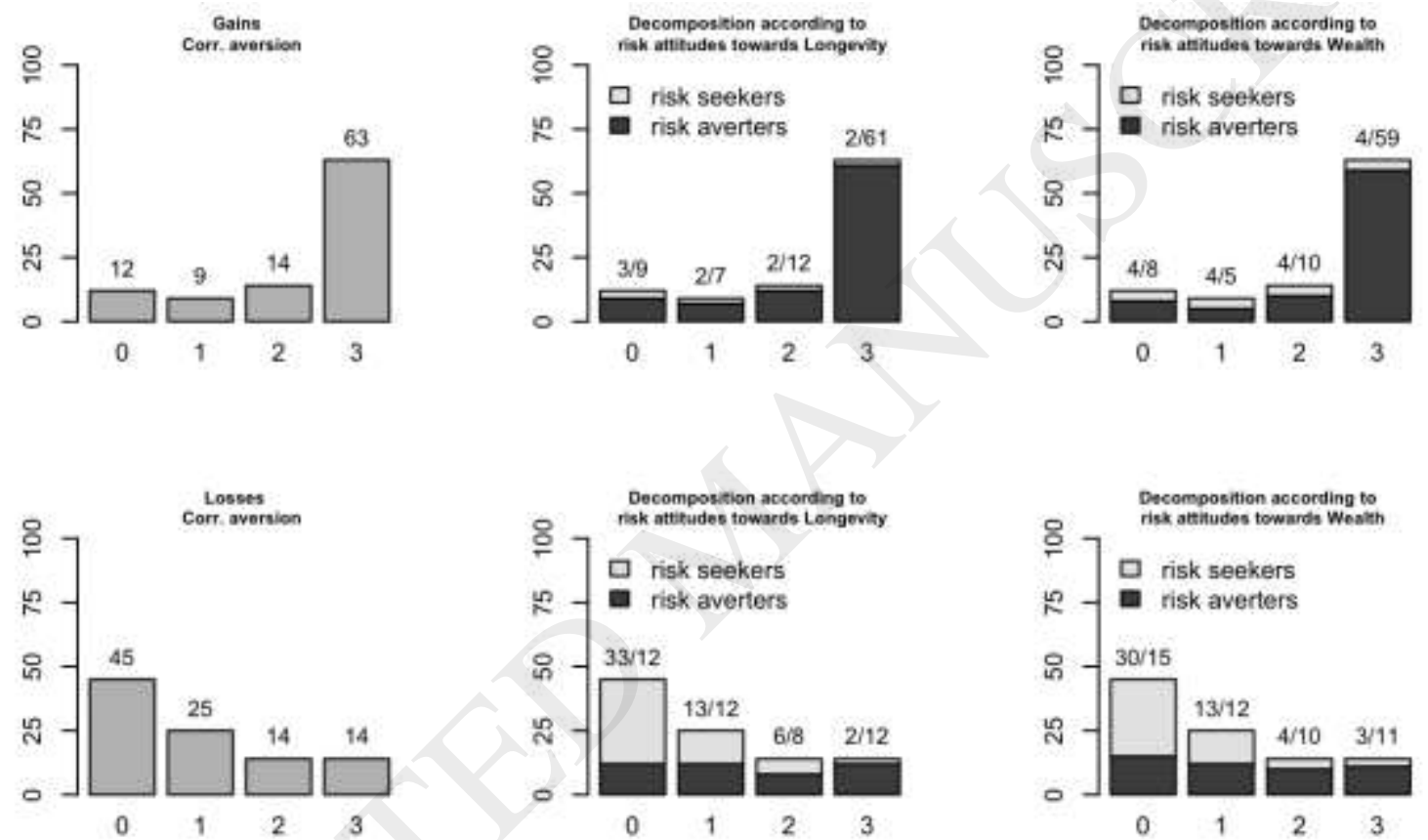

Figure 6: Correlation aversion for gains and losses, distribution of the number of correlation averse choices and decomposition according to univariate risk attitudes.

Cross-prudence is related to univariate prudence, but for gains only. Cross-prudence in longevity for related to prudence for wealth (Fisher test, p-value 0.004) and crossprudence for wealth is related to prudence for longevity (Fisher test, p-value 0). For 
losses, however, we observe no systematic association between multivariate crossprudence and univariate prudence (both p-values $>0.10$ ).

Figure 7 illustrates the relationship between cross-prudence and univariate prudence for gains. The corresponding Figure for losses can be found in Figure B-1 in Appendix B. Figure 7 also shows the distributions of the number of cross-prudent choices in longevity (top row) and in wealth (bottom row). Finally, Figure 7 shows the distributions of the number of corresponding cross-prudent choices for prudent and imprudent decision-makers in the univariate setting for both longevity and wealth.


Figure 7: Cross-prudence for gains, distribution of the number of cross-prudent choices in longevity (top row) and in wealth (bottom row) and decomposition according to univariate prudence. 
We also found a positive association between cross-temperance and temperance in the univariate context. This holds for longevity (Fisher test, p-value 0.024) and for wealth (Fisher test, p-value 0.002).

For gains, the combination of correlation aversion, cross-prudence and crossintemperance corresponded to the modal multivariate risk preference when crossprudence for wealth was considered (for $27.55 \%$ of subjects). When cross-prudence for longevity was considered, this combination, although shared by a minority of subjects ( $20.41 \%$ of subjects) was not the modal preference. Indeed, the combination of correlation aversion, cross-imprudence in longevity and cross-intemperance was shared by $23.47 \%$ of subjects. For losses, whatever the definition of cross-prudence, the modal multivariate risk preference revealed correlation seeking, cross-imprudence and cross-intemperance $(28.57 \%$ of subjects for cross-prudence in wealth, $28.57 \%$ of subjects for cross-prudence in longevity).

\section{Discussion}

In this study we have shown how univariate and multivariate risk attitudes for longevity and wealth can be measured in a direct way, without the need for any modeling assumptions. We have also been the first to measure cross-prudence and cross-temperance for wealth and longevity, and, more generally, the first to measure these traits in a sign-dependent framework.

Regarding univariate risk preferences, for monetary gains we confirm the common finding of risk aversion and prudence (see Trautmann and van de Kuilen, 2018). Moreover, we do not observe a strong preference toward temperance, which is in line with the mixed findings in the literature where some papers have observed a preference 
for intemperance (e.g., Deck and Schlesinger 2010; Baillon et al. 2018), while other studies have found the opposite (e.g., Deck and Schlesinger, 2014; Noussair et al., 2014). The fact that our findings in the wealth domain with hypothetical incentives confirm the common findings obtained under real incentives strengthens the recent observation by Trautmann and van de Kuilen (2018) that the provision of monetary rewards itself does not appear to affect preferences toward higher order risk. ${ }^{5}$

The pattern of risk aversion and prudence toward monetary gains extends toward higher order risk preferences regarding gains in longevity. People are not only risk averse, but also prudent for longevity. We replicate the shift toward neutrality when considering losses; in the loss domain, the modal choice pattern is indicative of neutrality toward risk and prudence. This finding corroborates recent results obtained by Bleichrodt and van Bruggen (2018), who observe a shift from risk aversion and modest prudence for gains to risk neutrality and imprudence for losses for monetary outcomes. Similar results were also reported by Smith et al. (2002), who found 73\% of choices for gains to be risk averse and $55.5 \%$ of choices to be risk seeking for losses, and others (e.g. Abdellaoui, 2000; Abdellaoui et al., 2008; Fehr-Duda and Epper, 2012). We extend these findings toward longevity risks.

Regarding multivariate risk preferences, we observe correlation aversion for wealth and longevity in the gain domain. Thus, people prefer to separate fixed improvements in wealth and longevity. This pattern is reversed when fixed deteriorations in wealth and longevity are considered, i.e., we observe a preference for correlation seeking, as predicted by Bleichrodt et al. (2003b) based on the finding of some studies that the

\footnotetext{
${ }^{5}$ This observation is mainly based on the findings by Noussair et al. (2014), who do not observe any differences in the degree of risk aversion, prudence, and temperance between a real and a hypothetical payoff condition in a representative sample of the Dutch population.
} 
marginal utility of income increases with increases in health (e.g. Sloan et al., 1998; Viscusi and Evans, 1990). This marked difference between gains and losses may be considered striking, and is perhaps due to the specific design used in the current study. Future research could therefore establish whether attitudes toward correlation between health and wealth are genuinely domain-specific or whether attitudes toward correlation depend on stimuli. The method introduced in this paper can be used to test these two explanations in any setting in a model-free way.

Overall, our results show that the elicitation of higher order risk attitudes is subject to sign-dependence. In our experiment, the signs of the outcomes had a large impact on decisions, with more noise for losses than for gains, and a reversal from correlation averse behavior for gains to correlation seeking behavior for losses. This implies that framing and sign-dependence are more important in the study of higher order risk attitudes than previously thought, since most theoretical studies on this topic do not account for the agents' initial endowment (Bleichrodt et al., 2003a; Courbage and Rey, 2006; Eeckhoudt et al., 2007). Therefore, one should be cautious when applying the risk apportionment technique to elicit preferences for health, especially when they involve losses. Another implication of our findings of sign-dependence lies in the physicianpatient interaction. If the heterogeneity of patients' preferences is measured by a risk apportionment technique, it is important to keep in mind the framing effects we found. If patients reveal different behavior for gains than for losses, it is hard to tell which preferences should be considered in the physician's treatment recommendation. This also raises the question as to whether such recommendations should be descriptive or normative. Because our results are descriptive, and we do not have separate information on the extent to which this behavior was caused by non-rational components (cf., for example, a study that disentangles risk aversion in a utility 
component and a probability weighting component), we are not able to draw firm normative conclusions from our study. However, the findings of sign-dependence suggest that, for normative purposes, it would be better to express the potential health outcomes in terms of final outcomes, instead of framing them as gains or loss relative to some reference points. It should be mentioned that a weakness of using a fixed reference point is that our results cannot be generalized to other reference points. This highlights the need for further research into this topic using different reference points.

Because this study comprises a new elicitation method, we used a convenience sample to test its feasibility and reliability. Future work could implement this methodology in a sample more representative of the general public, increasing external validity. Such work could also aim to verify some predictions that follow from our results, such as if differences exist in higher order risk attitudes between lower and higher incomes. This kind of findings would have large consequences for policy making. For instance, our finding of cross-prudence for wealth gains would imply that people who expect a health shock in the future will save more now than people who do not expect this, or than those who currently experience a health shock. In addition, the observation of correlation seeking for losses will lead retirees to anticipate that health deteriorations will boost their marginal utility of income due to impeded home production. The presence or not of spouses is also of special importance in this regard, since individuals with a spouse will have more possibilities for free informal care. As a result, they are less likely to have to hire a caregiver if they get sick, so they are less likely to be correlation seeking (Edwards, 1998).

Our results likewise have important implications for health insurance. Expectations about future health risks are related to expected future medical expenses and will therefore influence current health insurance decisions (e.g. amount of deductible, 
supplementary insurance) and savings. The degree of prudence for wealth will affect the reaction of current health insurance choice and savings to the increased future medical expenses risk; whereas, the degree of cross-prudence for wealth will affect the response of health insurance uptake to the future health risk. Moreover, the degree of correlation aversion is important here if one anticipates an adverse health shock; correlation averse [seeking] individuals will then spend [save] more now. For example, Rosen and Wu (2004) observed that poor health is associated with safer investment portfolios regardless of health insurance status or other medical expenditures. This implies the individuals studied by Rosen and Wu (2004) were cross-prudent for health status on the aggregate.

In the main analysis, we used the number of choices as a measure of the strength of preferences. As previously mentioned, this allows us to directly compare our results with the existing literature where this measure is used most (Deck and Schlesinger, 2014, 2010; Ebert and van de Kuilen, 2018; Noussair et al., 2014), and it provides a ranking of subjects in terms of these preferences without having to assume that subjects maximize a particular preference model, such as EU. A drawback is that our information about the amount of (higher order) risk aversion is admittedly limited. Future research should therefore strive toward more precise estimates of these risk attitudes, e.g. by eliciting the intensity of risk attitudes instead of only its sign, as for example performed by Ebert and Wiesen (2014) for univariate risk attitudes.

Another future research avenue is to investigate the combination of two different health risks, e.g. by considering two comorbidities, one affecting longevity, and one affecting quality of life. Bleichrodt et al. (2003a) have demonstrated the theoretical importance of these concepts, but thus far these theoretical predictions have not yet been empirically tested. The risk apportionment technique applied in this study may 
also be used in future work combining wealth and quality of life. Such an approach may bring more clarity on the sign of the cross-derivative of these two attributes, since, at present, there is mixed empirical evidence of the relation between marginal utility of wealth and health status. Some studies reported the marginal utility to increase with improved health status (Brown et al., 2015; Domeij and Johannesson, 2006; Finkelstein et al., 2013; Gyrd-Hansen, 2017; Sloan et al., 1998; Viscusi and Evans, 1990), whereas others report evidence for the opposite relation (Edwards, 2008; Evans and Viscusi, 1991; Lillard and Weiss, 1997; Tengstam, 2014).

Other interesting research topics would be the elicitation of higher order (multivariate) preferences for the health outcomes of different groups in society (i.e., equity attitudes, Courbage and Rey (2012)) and the elicitation of self-versus-other preferences à la Ebert and van de Kuilen (2018) in a health context. The latter could shed some light on the current debate about the role of relative positions in health (e.g. Wouters et al., 2015).

It has been observed that the degree of prudence compared to the degree of risk aversion typically observed in experiments is too strong to be adequately modeled by widely-used utility functions such as CARA or CRRA utility under EU. Moreover, risk averse individuals should be temperate under these specifications (e.g. Noussair et al., 2014; Trautmann and van de Kuilen, 2018). As a result, several papers have discussed the implications of attitudes towards higher order risk under non-EU models such as prospect theory in the wealth domain (e.g. Bleichrodt and Eeckhoudt, 2005; Bleichrodt and van Bruggen, 2018; Deck and Schlesinger, 2010, 2014). Our finding of strong risk aversion and temperance neutrality for monetary gains combined with the fact that attitudes toward higher order risk are more pronounced for gains than for losses add to the notion that investigating the implications of higher order risk under non-EU models 
is a fruitful avenue for future research. The fact that we observe the same behavioral pattern for outcomes in terms of longevity (i.e., strong risk aversion combined with temperance neutrality and sign-dependence) suggests that this discussion is also highly relevant for the health domain; attitudes toward higher order risk for longevity might be better captured by non-EU models. The measurements presented in this paper could serve as an input for the calibration of such models.

\section{Conclusion}

In this study we have shown how the risk apportionment technique can be applied to measure multivariate, higher order, risk preferences for longevity and wealth. In addition, we implemented a sign-dependent framework in order to test for differences between gains and losses. We observe that individuals in both domains are risk averse and prudent for gains, while they are closer to risk and prudence neutrality for losses. There is clear evidence that multivariate preferences are sign-dependent, with correlation aversion for gains and correlation seeking for losses. Therefore, we conclude that framing and sign effects are important factors in the experimental measurement of (higher order) multivariate risk preferences. 


\section{Acknowledgments}

This paper has benefited from the comments and suggestions of two anonymous

referees, Mathias Kifmann (the editor), participants of seminars at the University of Southern Denmark and Newcastle Business School, and participants of the FUR conference in York and the EUHEA conference in Maastricht. 


\section{References}

Abdellaoui, M., 2000. Parameter-Free Elicitation of Utility and Probability Weighting Functions. Manage. Sci. 46, 1497-1512.

https://doi.org/10.1287/mnsc.46.11.1497.12080

Abdellaoui, M., Baillon, A., Placido, L., Wakker, P.P., 2011. The rich domain of uncertainty: Source functions and their experimental implementation. Am. Econ. Rev. 101, 695-723.

Abdellaoui, M., Bleichrodt, H., l'Haridon, O., 2008. A tractable method to measure utility and loss aversion under prospect theory. J. Risk Uncertain. 36, 245-266.

Baillon, A., Bleichrodt, H., Spinu, V., 2017. Searching for the Reference Point.

Baillon, A., Schlesinger, H., van de Kuilen, G., 2018. Measuring higher order ambiguity preferences. Exp. Econ. 21, 233-256. https://doi.org/10.1007/s10683-017-9542-3

Bardsley, N., Cubitt, R., Loomes, G., Moffatt, P., Starmer, C., Sugden, R., 2009.

Experimental Economics: Rethinking the Rules. Princeton University Press.

Bleichrodt, H., Crainich, D., Eeckhoudt, L., 2003a. The effect of comorbidities on treatment decisions. J. Health Econ. 22, 805-820.

Bleichrodt, H., Crainich, D., Eeckhoudt, L., 2003b. Comorbidities and the willingness to pay for health improvements. J. Public Econ. 87, 2399-2406.

Bleichrodt, H., Eeckhoudt, L., 2005. Saving under rank-dependent utility. Econ. Theory $25,505-511$.

Bleichrodt, H., Pinto, J.L., 2000. A Parameter-Free Elicitation of the Probability Weighting Function in Medical Decision Analysis. Manage. Sci. 46, 1485-1496. https://doi.org/10.1287/mnsc.46.11.1485.12086

Bleichrodt, H., Pinto, J.L., Wakker, P.P., 2001. Making descriptive use of prospect theory to improve the prescriptive Use of expected utility. Manage. Sci. 47, 1498-1514. 
https://doi.org/10.1287/mnsc.47.11.1498.10248

Bleichrodt, H., van Bruggen, P., 2018. Higher order risk preferences for gains and losses.

Brown, J.R., Goda, G.S., McGarry, K., 2015. Heterogeneity in State-Dependent Utility:

Evidence from Strategic Surveys. Econ. Inq.

Cohen, J.D., Ericson, K.M., Laibson, D., White, J.M., 2016. Measuring time preferences, National Bureau of Economic Research. National Bureau of Economic Research.

Courbage, C., Rey, B., 2012. Priority setting in health care and higher order degree change in risk. J. Health Econ. 31, 484-489.

Courbage, C., Rey, B., 2006. Prudence and optimal prevention for health risks. Health Econ. 15, 1323-1327. https://doi.org/10.1002/hec.1138

Dardanoni, V., Wagstaff, A., 1990. Uncertainty and the demand for medical care. J. Health Econ. 9, 23-38.

De Finetti, B., 1952. Sulla preferibilita. G. degli Econ. e Ann. di Econ. 685-709.

Deck, C., Schlesinger, H., 2018. ON THE ROBUSTNESS OF HIGHER ORDER RISK PREFERENCES. J. Risk Insur. 85, 313-333. https://doi.org/10.1111/jori.12217

Deck, C., Schlesinger, H., 2014. Consistency of higher order risk preferences. Econometrica 82, 1913-1943.

Deck, C., Schlesinger, H., 2010. Exploring higher order risk effects. Rev. Econ. Stud. 77, $1403-1420$.

Domeij, D., Johannesson, M., 2006. Consumption and Health. B.E.Journal Macroecon. 6, 1-30.

Ebert, S., van de Kuilen, G., 2018. Measuring multivariate risk preferences.

Ebert, S., Wiesen, D., 2014. Joint measurement of risk aversion, prudence, and temperance. J. Risk Uncertain. 48, 231-252. https://doi.org/10.1007/s11166-0149193-0 
Ebert, S., Wiesen, D., 2011. Testing for Prudence and Skewness Seeking. Manage. Sci. 57, 1334-1349. https://doi.org/10.1287/mnsc.1110.1354

Edwards, R.D., 2008. Health risk and portfolio choice. J. Bus. Econ. Stat. 26, 472-485.

Eeckhoudt, L., Rey, B., Schlesinger, H., 2007. A good sign for multivariate risk taking. Manage. Sci. 53, 117-124.

Eeckhoudt, L., Schlesinger, H., 2006. Putting Risk in Its Proper Place. Am. Econ. Rev. 96, 280-289. https://doi.org/10.1257/000282806776157777

Epstein, L.G., Tanny, S.M., 1980. Increasing generalized correlation: a definition and some economic consequences. Can. J. Econ. 16-34.

Evans, W.N., Viscusi, W.K., 1991. Estimation of state-dependent utility functions using survey data. Rev. Econ. Stat. 94-104.

Fehr-Duda, H., Epper, T., 2012. Probability and Risk: Foundations and Economic Implications of Probability-Dependent Risk Preferences. Annu. Rev. Econom. 4, 567-593. https://doi.org/10.1146/annurev-economics-080511-110950

Felder, S., Mayrhofer, T., 2014. Risk preferences: consequences for test and treatment thresholds and optimal cutoffs. Med. Decis. Mak. 34, 33-41.

Finkelstein, A., Luttmer, E.F.P., Notowidigdo, M.J., 2013. WHAT GOOD IS WEALTH WITHOUT HEALTH? THE EFFECT OF HEALTH ON THE MARGINAL UTILITY OF CONSUMPTION. J. Eur. Econ. Assoc. 11, 221-258. https://doi.org/10.1111/j.15424774.2012.01101.x

Fischbacher, U., 2007. z-Tree: Zurich toolbox for ready-made economic experiments. Exp. Econ. 10, 171-178.

Gollier, C., Pratt, J.W., 1996. Risk vulnerability and the tempering effect of background risk. Econom. J. Econom. Soc. 1109-1123.

Gyrd-Hansen, D., 2016. A Stated Preference Approach to Assess whether Health Status 
Impacts on Marginal Utility of Consumption. Health Econ. n/a-n/a.

https://doi.org/10.1002/hec.3393

Kimball, M.S., 1993. Standard risk aversion. Econom. J. Econom. Soc. 589-611.

Kimball, M.S., 1990. Precautionary Saving in the Small and in the Large. Econom. J. Econom. Soc. 53-73.

Krieger, M., Mayrhofer, T., 2012. Patient Preferences and Treatment Thresholds under Diagnostic Risk - An Economic Laboratory Experiment. Rheinisch-Westfälisches Institut für Wirtschaftsforschung, Ruhr-Universität Bochum, Universität Dortmund, Universität Duisburg-Essen.

Lillard, L.A., Weiss, Y., 1997. Uncertain health and survival: Effects on end-of-life consumption. J. Bus. Econ. Stat. 15, 254-268.

Loomes, G., McKenzie, L., 1989. The use of QALYs in health care decision making. Soc. Sci. Med. 28, 299-308.

Maier, J., Rüger, M., 2011. Experimental evidence on higher order risk preferences with real monetary losses. Chapman Univ. (ESI), Work. Pap. 10-15.

Noussair, C.N., Trautmann, S.T., Van de Kuilen, G., 2014. Higher order risk attitudes, demographics, and financial decisions. Rev. Econ. Stud. 81, 325-355.

Pauker, S.G., 2014. Moments When Utilities Are Functional. Med. Decis. Mak. 34, 4-7. https://doi.org/10.1177/0272989X13495714

Pliskin, J.S., Shepard, D., Weinstein, M.C., 1980. Utility functions for life years and health status. Oper. Res. 28, 206-224.

Rey, B., Rochet, J.-C., 2004. Health and wealth: How do they affect individual preferences? Geneva Pap. Risk Insur. 29, 43-54.

Richard, S.F., 1975. Multivariate risk aversion, utility independence and separable utility functions. Manage. Sci. 22, 12-21. 
Sloan, F.A., Viscusi, W.K., Chesson, H.W., Conover, C.J., Whetten-Goldstein, K., 1998. Alternative approaches to valuing intangible health losses: The evidence for multiple sclerosis. J. Health Econ. 17, 475-497.

Smith, K., Dickhaut, J., McCabe, K., Pardo, J. V, 2002. Neuronal substrates for choice under ambiguity, risk, gains, and losses. Manage. Sci. 48, 711-718.

Starmer, C., 2000. Developments in non-expected utility theory: The hunt for a descriptive theory of choice under risk. J. Econ. Lit. 38, 332-382.

Stott, H., 2006. Cumulative prospect theory's functional menagerie. J. Risk Uncertain. 32, $101-130$.

Tengstam, S., 2014. DISABILITY AND MARGINAL UTILITY OF INCOME: EVIDENCE FROM HYPOTHETICAL CHOICES. Health Econ. 23, 268-282. https://doi.org/10.1002/hec.2912

Trautmann, S.T., van de Kuilen, G., 2018. Higher order risk attitudes: A review of experimental evidence. Eur. Econ. Rev. 103, 108-124.

Tversky, A., Kahneman, D., 1992. Advances in Prospect Theory: Cumulative Representation of Uncertainty. J. Risk Uncertain. 5, 297-323.

Viscusi, W.K., Evans, W.N., 1990. Utility Functions That Depend on Health Status: Estimates and Economic Implications. Am. Econ. Rev. 80, 353-374.

Wakker, P.P., 2010. Prospect theory: For risk and ambiguity. Cambridge University Press, Cambridge. 